\title{
The evolution of non-maternal caretaking among anthropoid primates: do helpers help?
}

Received: 28 May 1996 / Accepted after revision: 16 November 1996

\begin{abstract}
Non-maternal infant care among nonhuman primates has frequently been investigated from the perspective of the caretaker. Here we examine whether allocaretaking behavior provides direct reproductive benefits to mothers. Comparative analyses that control for the effects of allometry and phylogeny reveal that allocaretaking behavior correlates with relatively fast infant growth and reproduction, but is not associated with the production of large infants. These results are consistent with those from studies of other taxa; primate helpers appear to increase the reproductive success of female breeders. In addition, our findings contrast with those derived from traditional allometric analyses and underscore the importance of controlling for the potentially confounding effects of phylogeny in comparative analyses.
\end{abstract}

Key words Alloparental behavior · Primates · Comparative methods

\section{Introduction}

Non-maternal caretaking of young or "allocaretaking" is common in some mammalian taxa (Hrdy 1976; Gittleman 1985; Packer et al. 1992; Jennions and MacDonald 1994). Among nonhuman primates, allocaretaking behavior includes transporting infants (Chivers 1974; Wright 1984; Goldizen 1987a), food provisioning (Feistner and Price 1991), baby-sitting (Stanford 1992), and communal nursing (Williams et al. 1994; Perry 1995). In addition to providing care, non-

J.C. Mitani $(\bowtie) \cdot$ David Watts $^{1}$

Department of Anthropology, University of Michigan, Ann Arbor, MI 48109, USA

Fax: 203-432-3669; e-mail: dwatts@minerva.cis.yale.edu

Present address:

${ }^{1}$ Department of Anthropology, Box 208277, Yale University, New Haven, CT, 06520, USA maternal conspecifics sometimes mistreat infants (Hrdy 1976, 1977; Altmann 1980; Silk 1980; Maestripieri 1994). Allocaretaking in primates thus poses two related evolutionary questions: why should allocaretakers devote time and energy to care for infants of other individuals, and why should mothers tolerate non-mothers handling their infants given the risk of abuse?

The evolution of non-maternal caretaking has typically been addressed from the perspective of the caretaker (reviews in Hrdy 1976; McKenna 1979; Riedman 1982; Emlen 1991). In monogamous primates such as owl monkeys (Wright 1984) or facultatively polyandrous callitrichids (Goldizen 1987a,b), caretaking by males represents actual or potential paternal care. Several studies support the hypothesis that nulliparous females improve their maternal skills through allocaretaking and thereby increase the probability that their subsequent offspring will survive (e.g., saddle-backed tamarins: Goldizen 1987a; vervet monkeys: Lancaster 1971; Fairbanks 1990). Some evidence is also consistent with a second, non-mutually exclusive hypothesis: allocaretakers may increase their inclusive fitness by tending related infants. One compelling example is helping by marmosets and tamarins; when high dispersal costs and saturated habitats create poor breeding prospects, older offspring often remain in their natal groups and care for their younger siblings (Goldizen 1987a,b).

While previous research on allocaretaking among primates has focused primarily on the question of why helpers help, whether mothers benefit from the help provided by non-maternal caretakers has rarely been addressed in this taxon. Although the risk of infant abuse undoubtedly represents an important cost to mothers in many cases (Silk 1980; Maestripieri 1994), the benefits obtained via allocaretaking may outweigh these costs in certain situations. By providing relief from parental duties, non-maternal care may permit mothers to adjust their efforts to produce large and rapidly growing young or frequent litters. For example, the prevalence of non-maternal care among callitrichid pri- 
mates has been functionally related to the production of relatively large litters (Leutenegger 1980; Goldizen 1987b; Wright 1990). In addition, field observations indicate that mothers feed longer or at faster rates when their infants are tended by others compared with when they care for their infants themselves (vervets: Whitten 1984; langurs: Vogel 1984; Stanford 1992; tamarins: Goldizen 1987a; squirrel monkeys: L. Morton, personal communication). Augmented foraging success that results from allocaretaking could in turn translate directly into reproductive benefits by increasing postnatal growth rates (Ross 1991; Ross and MacLarnon 1995) or decreasing interbirth intervals (Fairbanks 1990).

In this paper we provide comparative tests of the hypothesis that mothers accrue direct reproductive benefits through non-maternal caretaking. Specifically, we examine whether species in which allocaretaking occurs produce relatively large infants and show high postnatal growth rates and short birth intervals compared with species in which mothers serve as primary caretakers.

\section{Methods}

\section{Variables}

We used the assessments of researchers who studied individual species in the wild to assign each to dichotomous allocaretaking and maternal categories. Our categories were defined on the basis of whether nonmaternal conspecifics frequently carried, provisioned, guarded, or nursed infants, and agree closely with independent classifications made by other researchers (e.g. Ross and MacLarnon 1995). In practice, carrying has been the principal behavioral category used to define allocaretaking among primates for theoretical and empirical reasons; carrying is the most energetically costly and frequently observed form of caretaking in which non-mothers engage (Lancaster 1971; Hrdy 1997; Goldizen 1987a; Small 1990; Wright 1990; Stanford 1992; Digby 1995). In the following, we restricted analysis to anthropoids because of the potentially confounding effects of "infant parking" on maternal energetics in some prosimians (Pereira et al. 1987).

We considered all non-maternal conspecifics potential allocaretakers. Thus, our allocaretaking category included species in which other females (e.g.,nulliparous females: Hrdy 1977), known or assumed fathers (e.g., monogamous males: Wright 1990), and prereproductive helpers (e.g., tamarins: Goldizen 1987a) care for infants other than their own. We do not attempt to distinguish paternal care from other non-maternal caretaking for two reasons. First, caretaking by adult male primates does not always represent paternal care (Baker et al. 1993; Paul et al. 1996). Second, whether male care constitutes paternal investment is not directly relevant to the reproductive energetics of mothers.

For our analyses of litter weights and postnatal growth, we employed litter weights, growth rates, and female body weights for anthropoid primates compiled by Lee and colleagues (Lee et al. 1991), supplemented with data for callitrichids assembled by Ross $(1989,1991)$. Postnatal growth rates were computed by subtracting litter weights at birth from litter weights at weaning and dividing by the age at weaning. Similar litter weights can result from different combinations of litter size and individual weights. For example, females may give birth to a single, large offspring or bear two smaller young half the size. Maternal expenditures would be markedly different in the two situations since metabolic requirements increase in a decreasing fashion with size (Kleiber 1975). As a result, the cost of two small young would exceed that of a sin- gleton of equivalent size. Given these considerations, we employed the metabolic weights of litters at birth and weaning in our analyses of growth. The majority of primates give birth to single infants at a time, and for these species we computed the metabolic weight of litters by raising infant weights to the 0.75 power (Kleiber 1975). For callitrichid species that typically give birth to multiple offspring, we calculated the metabolic weights of singletons and multiplied the growth of these individuals by the average number of infants per litter.

The data employed in our analyses of litter weights and postnatal growth are based on individuals living in the wild as well as in captivity (Lee et al. 1991; Ross 1989, 1991), and for this reason, may be less than ideal. We attempted to employ a uniform and biologically relevant data set to analyze the effects of allocaretaking on female reproduction by using observations of birth intervals and female body weights of free-ranging females. To control for the potentially confounding effect of infant mortality, we employed the mean birth intervals of females whose previous infants had survived whenever possible.

\section{Analyses}

We began by performing a set of traditional analyses using individual species as data points. We employed the residuals of linear regressions between female body weight and (1) litter weight, (2) postnatal growth rate, and (3) birth interval as allometrically corrected measures of these three variables and used Student's $t$-tests to compare residual litter weights, residual growth rates, and residual birth intervals between allocaretaking and maternal species. We performed model I regressions since the residuals generated through this technique are uncorrelated with the dependent variable (Harvey and Pagel 1991). We conducted all analyses using logarithmically transformed variables and standardized residual litter weights, growth rates, and birth intervals before conducting statistical tests.

The preceding analyses do not control for the potentially confounding effects of phylogeny. We therefore employed the method of independent contrasts (Burt 1989) to examine the relationship between the presence or absence of allocaretaking and (1) litter weights, (2) infant growth rates, and (3) birth intervals. This technique employs an inferred phylogeny to obtain a set of independent comparisons or contrasts between pairs of extant taxa that differ in the trait of interest, in this case allocaretaking. Independent contrasts were performed using the "brunch" algorithm implemented on the Comparative Analysis by Independent Contrasts (CAIC) program for the MacIntosh (Purvis and Rambaut 1995).

We used a $t$-test on the mean of the contrasts to test the null hypothesis that the evolution of litter weight, infant growth, or birth interval is unrelated to the evolution of allocaretaking. Under the null hypothesis, we expect the mean value of the contrasts to be zero; mean values significantly greater than zero suggest that high litter weights and growth rates or long birth intervals are correlated with the evolution of allocaretaking. We conducted our tests using a consensus tree based on neontological and paleontological evidence (Purvis 1995). Additional tests employing alternative phylogenies (e.g., Sarich and Cronin 1976) produced results that were consistent with those derived from the consensus tree.

The allometrically corrected values of litter weight, postnatal growth, and birth interval that we employed in the independent contrasts were not the same as those used in the traditional allometric analysis described above. To obtain values for these tests, we computed the regression of the contrasts of litter weight, growth, and birth interval against the contrasts of female weight. We assume the regressions of these contrasts to represent the best estimates of the evolutionary relationships between the three variables and female weight (Purvis and Rambaut 1994). After calculating these model I regressions, we fit lines of identical slope to the original bivariate plots of (1) litter weight and female weight, (2) postnatal growth rate and female weight, (3) birth interval and female weight. We employed the residuals from these lines as our allometrically and phylogenetically corrected measures of litter weight, infant growth, and birth interval (Purvis and Rambaut 1994). 
Independent contrasts require specification of phylogenetic branch lengths, and we used estimates of these times based on the fossil record and molecular clocks as reported by Purvis (1995). Results of our analyses appear robust with respect to estimates of these divergence times. Alternative tests in which we assumed branch lengths to be equal produced results similar to those in which we provided estimates of branch lengths. To facilitate presentation, we present only results of the latter analyses. All contrasts were calculated on logarithmically transformed variables.

\section{Results}

Table 1 lists the data for female weights, litter weights, postnatal growth, and our classification of allocaretaking. Thirty-one species, including New World monkeys, Old World monkeys, and apes, were represented in the sample. Body weights and birth intervals of wild females were available for 28 of these 31 species (Table 2).

We conducted model I regressions using individual species as data points to derive allometrically-corrected values of litter weight, postnatal growth, and birth intervals. Figure 1a shows the standardized residual litter weights for the 31 species in our data set. A $t$-test revealed no difference in litter weights between species who have helpers and those who do not $(t=0.21,29 d f$,
$P>0.80)$. An examination of residual growth rates indicated that infant growth did not differ between the two sets of species (Fig. 1b; $t=0.78,29 d f, P>0.40$ ). Similarly, helpers do not appear to increase the rate at which females produce young; mothers who are assisted by helpers do not give birth more frequently than females who serve as the primary caretaker of their infants (Fig. $1 \mathrm{c} ; t=1.67,26 d f, P>0.10$ ).

The allocaretaking species in our sample represent a few taxa, notably the Callitrichidae (Fig. 2), and phylogenetic effects are likely to bias the preceding analyses. To control for the potentially confounding effects of phylogeny, we performed independent contrasts using the consensus tree (Fig. 2). Five contrasts in litter weight, postnatal growth, and birth interval were available between taxa who vary in infant caretaking styles (Fig. 2). Independent contrasts revealed that litter weights did not differ significantly between taxa with different infant care systems (Fig. 3; $t=0.30,4 d f$, $P>0.75)$. Infants of allocaretaking species, however, grow significantly faster than the young of maternal species (Fig. 3; $t=3.25,4 d f, P<0.05$ ). Assistance by helpers also has a direct effect on female reproduction; females of allocaretaking species give birth more often than mothers who care for their offspring alone (Fig. 3; $t=4.64,4 d f, P<0.01)$.

Table 1 Female body weights, litter weights, postnatal growth rates, and the presence or absence of non-maternal care in anthropoid primates. Weights and growth rates were compiled by Lee et. al. (1991) and Ross $(1989,1991)$. See text for methods used to calculate growth rates. References indicate sources employed to classify infant care systems

\begin{tabular}{|c|c|c|c|c|c|}
\hline Species & $\begin{array}{l}\text { Female body } \\
\text { weight }(\mathrm{kg})\end{array}$ & $\begin{array}{l}\text { Litter } \\
\text { weight }(\mathrm{kg})\end{array}$ & $\begin{array}{l}\text { Postnatal growth } \\
\text { rate (g/ day) }\end{array}$ & $\begin{array}{l}\text { Non-maternal } \\
\text { care }\end{array}$ & Reference \\
\hline Alouatta palliata & 6.00 & 0.318 & 0.23 & No & M. Clarke, pers. comm. \\
\hline Aotus trivirgatus & 1.00 & 0.098 & 0.44 & Yes & Wright 1984 \\
\hline Ateles geoffroyi & 8.40 & 0.426 & 0.52 & No & C. Chapman, pers. comm. \\
\hline Callimico goeldii & 0.62 & 0.051 & 0.53 & Yes & Pook 1984 \\
\hline Callithrix jacchus & 0.35 & 0.027 & 0.61 & Yes & L. Digby 1995 \\
\hline Cebuella pygmaea & 0.16 & 0.015 & 0.39 & Yes & P. Soini 1987 \\
\hline Cebus albifrons & 2.60 & 0.232 & 0.45 & Yes & Robinson and Janson 1987 \\
\hline Cebus apella & 2.90 & 0.239 & 0.32 & Yes & Robinson and Janson 1987 \\
\hline Cercocebus albigena & 7.50 & 0.500 & 1.03 & No & W. Olupot, pers. comm. \\
\hline Cercopithecus aethiops & 3.00 & 0.430 & 0.53 & Yes & Lancaster 1971 \\
\hline Cercopithecus neglectus & 4.00 & 0.260 & 0.46 & No & J. Wahome, pers. comm. \\
\hline Colobus guereza & 9.30 & 0.445 & 0.47 & Yes & Oates 1977 \\
\hline Erythrocebus patas & 5.60 & 0.625 & 0.85 & Yes & Zucker and Kaplan 1981 \\
\hline Gorilla gorilla & 93.00 & 2.110 & 1.51 & No & Watts, pers. observation \\
\hline Hylobates lar & 5.30 & 0.400 & 0.13 & No & Palombit, pers. comm. \\
\hline Leontopithecus rosalia & 0.66 & 0.050 & 0.22 & Yes & Baker et al. 1993 \\
\hline Macaca arctoides & 8.00 & 0.489 & 0.58 & No & Estrada \& Estrada 1984 \\
\hline Macaca fascicularis & 4.30 & 0.375 & 0.79 & No & C. van Schaik, pers. comm. \\
\hline Macaca fuscata & 9.20 & 0.503 & 0.44 & No & Hiraiwa 1981 \\
\hline Macaca mulatta & 8.50 & 0.473 & 0.61 & No & Lindburg 1971 \\
\hline Macaca sylvanus & 13.30 & 0.450 & 1.18 & Yes & Small 1990 \\
\hline Pan paniscus & 32.00 & 1.400 & 0.61 & No & Kano 1992 \\
\hline Pan troglodytes & 31.00 & 1.750 & 0.37 & No & Nishida 1983 \\
\hline Papio anubis & 13.90 & 0.950 & 0.52 & No & Nicolson 1982 \\
\hline Papio cynocephalus & 11.00 & 0.710 & 0.60 & No & Altmann 1980 \\
\hline Papio hamadryas & 12.00 & 1.000 & 0.42 & No & Kummer 1968 \\
\hline Pongo pygmaeus & 40.00 & 1.728 & 1.12 & No & J. Mitani pers. observation \\
\hline Presbytis vetulus & 7.80 & 0.360 & 0.40 & Yes & R. Rudran, pers. comm. \\
\hline Saguinus oedipus & 0.53 & 0.044 & 0.81 & Yes & Savage 1990 \\
\hline Saimiri sciureus & 0.60 & 0.146 & 0.25 & Yes & L. Morton, pers. comm. \\
\hline Theropithecus gelada & 13.60 & 0.465 & 0.73 & No & Dunbar and Dunbar 1975 \\
\hline
\end{tabular}


Table 2 Body weights and birth intervals of free-ranging female primates

\begin{tabular}{|c|c|c|c|}
\hline Species & $\begin{array}{l}\text { Female body } \\
\text { weight }(\mathrm{kg})\end{array}$ & $\begin{array}{l}\text { Interbirth } \\
\text { interval (y) }\end{array}$ & Reference \\
\hline Alouatta palliata & 4.02 & 1.88 & Glander 1980; Glander et al. 1991 \\
\hline Aotus trivirgatus & 0.93 & 1.00 & Ayres 1986; Wright 1990 \\
\hline Ateles geoffroyi & 6.62 & 2.73 & Glander et al. 1991; Fedigan and Rose 1995 \\
\hline Callithrix jacchus & 0.33 & 0.55 & L. Digby, pers. comm. \\
\hline Cebuella pygmaea & 0.14 & 0.50 & Soini 1982; Ayres 1986 \\
\hline Cebus albifrons & 2.23 & 1.50 & Defler 1979; Robinson and Janson 1987 \\
\hline Cebus apella & 2.45 & 1.83 & Ayres 1986; Robinson and Janson 1987 \\
\hline Cercopithecus aethiops & 2.57 & 1.43 & Cheney et al. 1988; Turner et al. 1994 \\
\hline Cercopithecus neglectus & 3.96 & 2.00 & Gautier-Hion 1975; Wahome et al. 1993 \\
\hline Colobus guereza & 7.90 & 1.10 & Struhsaker and Leland 1987; Oates et al. 1994 \\
\hline Erythrocebus patas & 6.20 & 1.00 & Chism, pers. comm.; Gonzalez-Martinez, pers. comm. \\
\hline Gorilla gorilla & 97.70 & 3.92 & Jungers and Susman 1984; Watts 1991 \\
\hline Hylobates lar & 5.30 & 2.90 & Schultz 1941; Palombit, pers. comm. \\
\hline Leontopithecus rosalia & 0.60 & 0.85 & Dietz et al. 1994 \\
\hline Macaca fascicularis & 3.50 & 1.90 & van Schaik, pers. comm. \\
\hline Macaca fuscata & 8.73 & 2.27 & Iwamoto 1971; Maruhashi 1982 \\
\hline Macaca mulatta & 5.40 & 2.17 & Napier 1981; Melnick and Pearl 1987 \\
\hline Macaca sylvanus & 9.92 & 1.28 & Menard and Vallet 1993; Vallet and Menard, pers. comm. \\
\hline Pan paniscus & 33.20 & 4.50 & Jungers and Susman 1984; Takahata et al. in press \\
\hline Pan troglodytes & 35.20 & 6.04 & Uehara and Nishida 1987; Nishida et al. 1990 \\
\hline Papio anubis & 12.71 & 2.08 & Smuts and Nicolson 1989 \\
\hline Papio cynocephalus & 11.90 & 1.75 & Altmann et al. 1977; Altmann et al. 1993 \\
\hline Papio hamadryas & 11.00 & 1.83 & Phillips-Conroy and Jolly 1981; Sigg et al. 1982 \\
\hline Pongo pygmaeus & 37.80 & 7.65 & Rodman 1984; Galdikas and Woods 1990 \\
\hline Presbytis vetulus & 7.10 & 1.60 & Rudran 1973; Davies 1994 \\
\hline Saguinus oedipus & 0.50 & 1.18 & Dawson and Dukelow 1976; Savage et al. 1996 \\
\hline Saimiri sciureus & 0.75 & 2.00 & Mitchell 1990; Mitchell et al. 1991 \\
\hline Theropithecus gelada & 13.95 & 2.14 & Kawai 1979; Dunbar 1984 \\
\hline
\end{tabular}

\section{Discussion}

Previous research reveals that helpers increase the reproductive performance of breeders in communal birds and mammals (review in Emlen 1991). Among nonhuman primates, correlations exist between allocaretaking and rapid infant growth and reproduction in Callitrichid primates (Goldizen 1987b; Ross 1991; cf. Fairbanks 1990). The results of the independent contrasts tests indicate the general applicability of these observations; clear associations hold between allocaretaking and fast postnatal growth and short birth intervals across the anthropoid primates (cf. Ross and MacLarnon 1995). These findings differ from those of traditional, comparative, allometric analyses (e.g., Tardif 1994), and stress the need to control for the potentially confounding effects of phylogeny. In addition, our results do not support the suggestion that relatively high litter weights are causally related to allocaretaking across the primate order (Leutenegger 1980; Goldizen 1987a,b; Wright 1990).

Although allocaretaking appears to be associated with rapid infant growth and reproduction in callitrichid primates (Goldizen 1987b; Ross 1991), data on the relationships between the quantity of allocaretaking and growth rates and reproduction are generally unavailable for particular primate species. The only reported data indicate that captive vervet mothers who receive considerable help raising their offspring show shorter birth intervals than females who receive less help (Fairbanks
1990). While the primate data bearing on this issue are limited, additional comparative observations of other cooperatively breeding mammals and birds show the expected relationships. For example, prairie vole pups grow faster with helpers than without them, and after the production of large litters, females with helpers experience shorter birth intervals than those who raise their offspring alone (Solomon 1991). Although the number of helpers has no effect on pup growth rates, female pine voles with several helpers have shorter birth intervals than those with few or none (Powell and Fried 1992). Similarly, the amount of help that breeding Florida scrub jays receive correlates positively with infant growth rates, and weight at fledging shows a strong positive correlation with fledging survival (Mumme 1992).

The analyses presented above are correlational and posit functional relationships between allocaretaking and infant growth and reproduction. We assume that accelerated growth and concomitant shortened birth intervals are, in turn, selectively advantageous for several reasons. First, infants and juveniles are more susceptible than adults to predation (Janson and van Schaik 1993; Stanford et al. 1994), and early attainment of large body size could reduce this risk. In this context we note that allocaretaking characterizes the Callitrichidae and the small-bodied Cebidae among New World monkeys and that it is found in vervet and patas monkeys, two terrestrial, savanna-dwelling Old World monkeys (Table 1). Predation pressure is demonstrably high for some of these species (tamarins: Goldizen 
a.

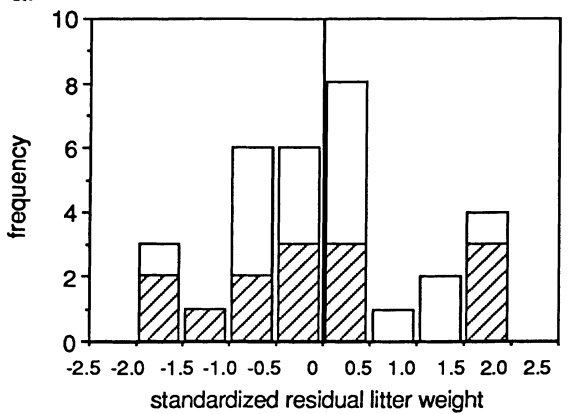

b.

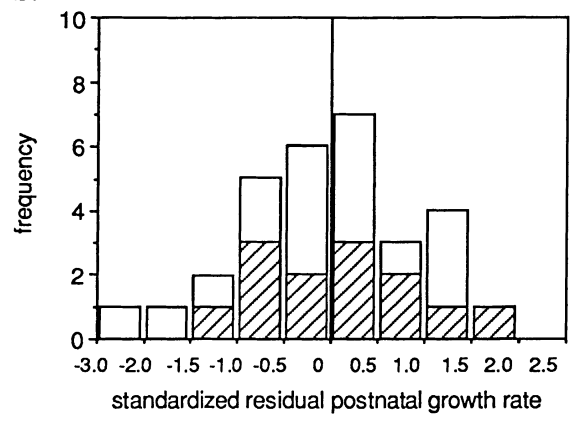

c.

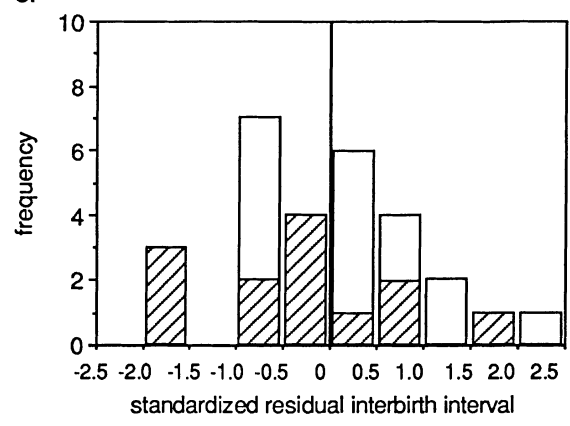

Fig. 1 Frequency distributions of standardized residual a litter weight; b postnatal growth rate and $\mathbf{c}$ interbirth interval. Residual values were computed from regressions of litter weight, growth, and birth interval versus female body weight

1987b; squirrel monkeys: Boinski 1987; vervets: Isbell 1990). Second, males commit infanticide in many primate species (Hiraiwa-Hasegawa 1988). Unlike the risk of predation, the threat of infanticide stops at weaning. Non-maternal caretaking could reduce this threat through the early weaning of infants. Third, rapid growth can improve the competitive abilities of juvenile males when size and weight influence the outcome of contests; accelerated growth could have the same effect on adult male competitive ability if it leads to large adult size (Clutton-Brock et al. 1982; Lee et al. 1991; Pereira 1993, 1995). Similar effects may apply to females when they disperse and must establish territories (e.g., callitrichids; Goldizen 1987a,b) or when they fail to form nepotistic dominance hierarchies (e.g., colobine monkeys: van Schaik 1989). Finally, relatively large size at

weaning could decrease juvenile starvation risk because of the lower metabolic requirements of large individuals (Lee et al. 1991) and because accumulated nutritional reserves can carry juveniles through seasons of food shortage (Pereira 1993).

Where the benefits to mothers are high, the evolution of allocaretaking may still be constrained by the behavior of potential helpers or by even higher costs associated with non-maternal caretaking. Allocaretaking may occur only rarely in species where the potential for abuse by non-mothers is high (Maestripieri 1994). The potential for abuse represents one of several maternal costs of allocaretaking, and may be reduced in ecological situations where local resource competition among females is low and contest competition for food has little effect on female fitness (Maestripieri 1994). These circumstances may characterize most colobines (van Schaik 1989) and Costa Rican squirrel monkeys (Saimiri oerstedi, Mitchell et al. 1991). In these species females do not form strong dominance hierarchies and have little to gain from harassing unrelated infants (cf. Dunbar 1984). The risk of infant abuse may also be reduced if egalitarian dominance relationships among females facilitate maternal retrieval of infants (McKenna 1979). Maternal costs should also be low when the provision of high quality infant care raises the inclusive fitness of allocaretakers (see Introduction). Finally, allocaretaking behavior may diminish its own costs through interaction with other factors. In situations where allocaretaking leads to high costs of lactation, the two may begin to coevolve and reinforce each other in an increasing fashion to a point at which the costs cannot be met without the aid of allocaretakers. Among some species of social carnivores subordinate females appear to forego reproduction if their energetic costs of reproduction are especially high (Creel and Creel 1991). In these circumstances, mothers may relinquish their offspring to conspecifics who remain within their natal group to accrue the inclusive fitness benefits derived through allocaretaking.

Although the results of the preceding analyses clarify some of the selective factors leading to the evolution of non-maternal caretaking, several questions remain unresolved. For example, why should parous adult female langurs care for infants of unrelated females (Vogel 1984; Stanford 1992)? If uniform benefits in terms of infant growth and female reproduction are derived through allocaretaking, why does non-maternal care occur infrequently in those species in which (a) maternal costs are low due to egalitarian female dominance relationships and reduced feeding competition and (b) interest in infants and attempts to handle them are high, e.g., in gorillas (Watts 1994)? What factors account for the relative rarity of allocaretaking in cercopithecine monkeys, e.g., patas monkeys and barbary macaques, and its absence among the apes? While the taxonomically disjunct appearance of non-maternal caretaking across the primate order (see Fig. 2 and reviews in Hrdy 1976; Nicholson 1987) has made the search for ecolog- 


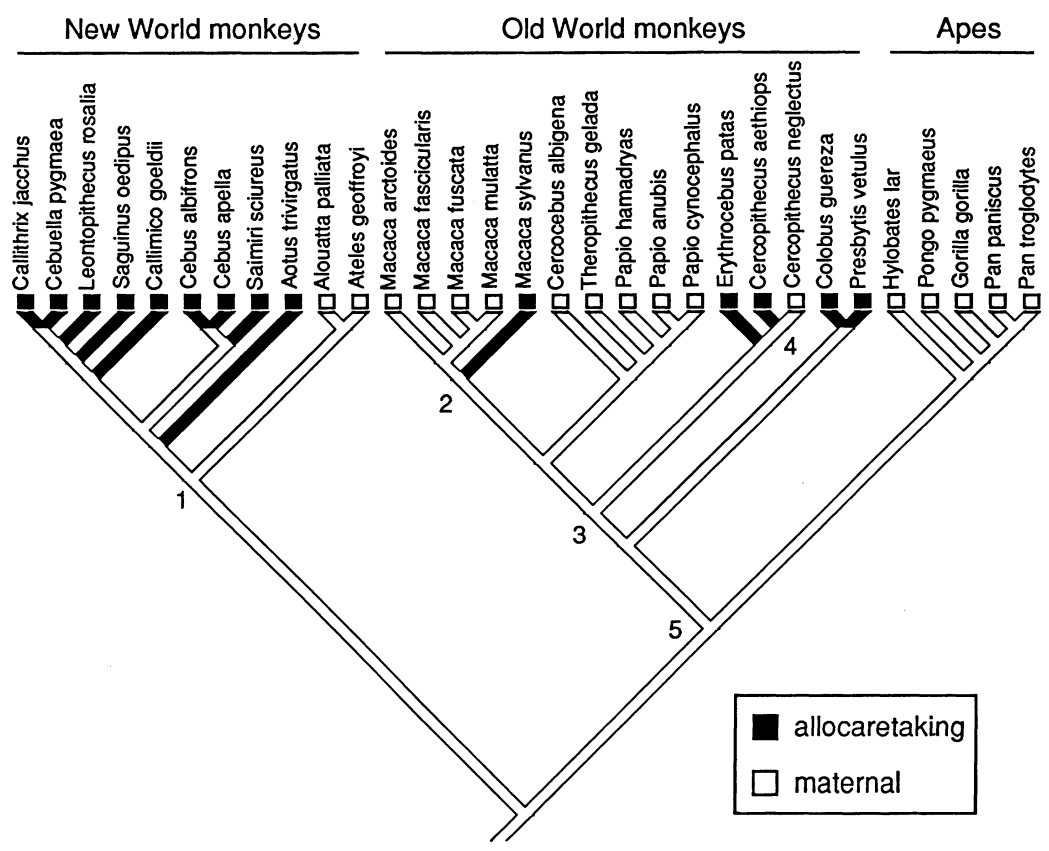

Fig. 2 A primate phylogeny. The phylogeny represents a consensus tree based on molecular, karotypic, paleontological, morphological, and behavioral data (Purvis 1995). Species who engage in allocaretaking behavior are denoted. Independent contrasts were performed

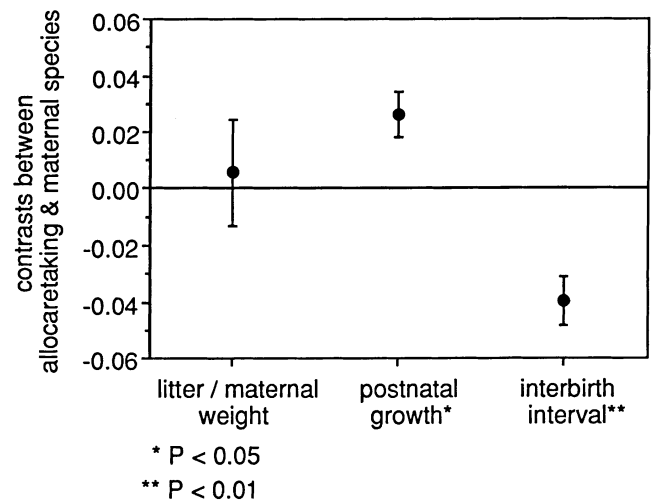

Fig. 3 Contrasts between allocaretaking and maternal species in litter weights, postnatal growth rates, and interbirth intervals. Mean \pm SE differences between allocaretaking and maternal species are plotted. * $\mathrm{P}<0.05$. ** $\mathrm{P}<0.01$.

ical and behavioral correlates difficult, comparative analyses will continue to provide a principal means to address these questions. In addition, intraspecific comparisons involving populations that show variations in the form and frequency of non-maternal caretaking promise to facilitate identifying the costs and benefits associated with the evolution of allocaretaking behavior.

Acknowledgements We thank the following colleagues for providing unpublished data: C. Chapman, J. Chism, M. Clarke, L. Digby, J. Gonzalez-Martinez, L. Morton, W. Olupot, R. Palombit, R. Rudran, A. Savage, C. van Schaik, and J. Wahome. We are especially indebted to Drs. D. Vallet and N. Menard of CNRS URA 373 for providing the weights of wild female Barbary macaques and to C. Ross for the use of weanling weights and the times of weaning at the five numbered nodes and correspond to the following: 1 Alouatta, Ateles vs. other New World monkeys; 2 Macaca sylvanus vs. other macaques; 3 Erythrocebus vs. Cercocebus -baboon clade; 4 C. aethiops vs. C. neglectus; 5 colobines vs. apes for Callitrichids. We are grateful to A. Purvis for supplying the Comparative Analysis by Independent Contrasts program, to C. Chapman, P. Harvey, W. Holmes, M. Huffman, P. Kappeler, M. Mitani, S. Perry, A. Purvis, D. Rendall, A. Richards, C. Ross, C. Sims-Parr, P. Waser, and an anonymous reviewer for advice, discussion, and comments on the manuscript, and to J. Gros-Louis and K. Race for assistance during data collection and analysis. Research was supported by a NSF Presidential Faculty Award SBR-9253590 to John Mitani.

\section{References}

Altmann J (1980) Baboon mother and infants. Harvard University Press, Cambridge

Altmann J, Altmann S, Hausfater G, McCuskey S (1977) Life history of yellow baboons: Physical development, reproductive parameters and infant mortality. Primates 18:315-330

Altmann J, Schoeller D, Altmann S, Muruthi P, Sapolsky R (1993) Body size and fatness in free-living baboons reflect food availability and activity levels. Am J Primatol 30:149-161

Ayres JM (1986) Uakaris and Amazonian flooded forest. PhD thesis, University of Cambridge

Baker A, Dietz J, Kleiman D (1993) Behavioural evidence for monopolization of paternity in multi-male groups of golden lion tamarins. Anim Behav 46:1091-1103

Boinski S (1987) Birth synchrony in squirrel monkeys (Saimiri oerstedi). A strategy to reduce neonatal predation. Behav Ecol Sociobiol 21:393-400

Burt A (1989) Comparative methods using phylogenetically independent contrasts. Oxford Surv Evol Biol 6:33-53

Cheney D, Seyfarth R, Andelman S, Lee P (1988) Reproductive success in vervet monkeys. In: Clutton-Brock $\mathrm{T}$ (ed) Reproductive success. University of Chicago Press, Chicago, pp 384 402

Chivers D (1974) The siamang in Malaya. Karger, Basel

Clutton-Brock T (1991) The evolution of parental care. Princeton University Press, Princeton 
Clutton-Brock T, Guinness F, Albon S (1982) Red deer: the behaviour and ecology of two sexes. University of Chicago Press, Chicago

Creel S, Creel N (1991) Energetics, reproductive suppression and obligate communal breeding in carnivores. Behav Ecol Sociobiol 28:263-270

Davies A (1994) Colobine populations. In: Davies AG, Oates J (eds) Colobine monkeys: their ecology, behaviour and evolution. Cambridge University Press, Cambridge, pp 285-310

Dawson G, Dukelow WR (1976) Reproductive characteristics of free-ranging Panamanian tamarins (Saguinus oedipus geoffroyi). J Med Primatol 5:266-275

Defler T (1979) On the ecology and behavior of Cebus albifrons in northern Columbia.1 Ecology. Primates 20:475-490

Dietz JM, Baker AJ, Miglioretti D (1994) Seasonal variation in reproduction, juvenile growth, and adult body mass in golden lion tamarins (Leontopithecus rosalia). Am J Primatol 34:115-132

Digby L (1995) Infant care, infanticide, and female reproductive strategies in polygynous groups of common marmosets. Behav Ecol Sociobiol 37:51-61

Dunbar R (1984) Reproductive decisions. An economic analysis of gelada baboon social strategies. Princeton University Press, Princeton

Dunbar R, Dunbar E (1975) Social dynamics of gelada baboons. Karger, Basel

Emlen S (1991) Evolution of cooperative breeding in birds and mammals. In: Krebs J, Davies N (eds) Behavioural ecology, 3rd edn. Blackwell, Oxford, pp 301-335

Estrada A, Estrada R (1984) Female-infant interactions among free-ranging stumptail macaques (Macaca arctoides). Primates 25:48-61

Fairbanks L (1990) Reciprocal benefits of allomothering for female vervet monkeys. Anim Behav 40:553-562

Fedigan L, Rose L (1995) Interbirth interval variation in three sympatric species of neotropical monkeys. Am J Primatol 37:924

Feistner A, Price E (1991) Food offering in New World primates: two species added. Folia Primatol 57:165-168

Galdikas B, Wood J (1990) Birth spacing patterns in humans and apes. Am J Phys Anthropol 83:185-193

Gautier-Hion A (1975) Dimorphisme sexuelle et organisation sociale chez les cercopithecines forestiers africains. Mammalia 39:365-374

Gittleman J (1985) Functions of communal care in mammals. In: Greenwood P, Harvey P, Slatkin M (eds), Evolution: essays in honor of J. Maynard Smith. Cambridge University Press, Cambridge, pp 187-205

Glander K (1980) Reproduction and population growth in freeranging mantled howling monkeys. Am J Phys Anthropol 53:25-36

Glander K, Fedigan LM, Fedigan L, Chapman C (1991) Field methods for capture and measurement of three monkey species in Costa Rica. Folia Primatol 57:70-82

Goldizen A (1987a) Facultative polyandry and the role of infantcarrying in wild saddle-back tamarins (Saguinus fuscicollis). Behav Ecol Sociobiol 20:99-109

Goldizen A (1987b) Tamarins and marmosets: Communal care of offspring. In: Smuts B, Cheney D, Seyfarth R, Wrangham R, Struhsaker T (eds), Primate societies. University of Chicago Press, Chicago, pp 3443

Harvey P, Pagel M (1991) The comparative method in evolutionary biology. Oxford University Press, Oxford

Hiraiwa M (1981) Maternal and alloparental care in a troop of free-ranging Japanese monkeys. Primates 22:309-329

Hiraiwa-Hasegawa M (1988) Adaptive significance of infanticide in primates. Trends Ecol Evol 3:102-105

Hrdy S (1976) Care and exploitation of nonhuman primate infants by conspecifics other than the mother. In: Rosenblatt J, Hinde $\mathrm{R}$, Shaw E, Beer C (eds), Advances in the study of behavior. Academic Press, New York, pp 101-158

Hrdy S (1977) The langurs of Abu. Harvard University Press, Cambridge
Isbell L (1990) Sudden short-term increase in mortality of vervet monkeys (Cercopithecus aethiops) due to leopard predation in Amboseli National Park, Kenya. Am J Primatol 21:41-52

Iwamoto M (1971) Morphological studies of Macaca fuscata. VI. Somatometry. Primates 12:151-174

Janson C, Schaik C van (1993) Ecological risk aversion in juvenile primates: slow and steady wins the race. In: Pereira M, Fairbanks L (eds), Juvenile primates. Oxford University Press, New York, pp 57-76

Jennions M, MacDonald D (1994) Cooperative breeding in mammals. Trends Ecol Evol 9:89-93

Jungers W, Susman R (1984) Body size and skeletal allometry in African apes. In: Susman R (ed) The pygmy chimpanzee: evolutionary biology and behavior. Plenum, New York, pp 131-177

Kano T (1992) The last ape. Stanford University Press, Stanford

Kawai M (1979) Auditory communication and social relations. In: Kawai M (eds), Ecological and sociological studies of gelada baboons. Karger, Basel, pp 219-241

Kleiber M (1975) The fire of life. Wiley, New York

Kummer H (1968) Social organization of hamadryas baboons. University of Chicago Press, Chicago

Lancaster J (1971) Play-mothering: the relations between juvenile females and young infants among free-ranging vervet monkeys (Cercopithecus aethiops). Folia Primatol 15:161-182

Lee P, Majluf P, Gordon I (1991) Growth, weaning and maternal investment from a comparative perspective. J Zool 225:99- 114

Leutenegger W (1980) Monogamy in callitrichids: a consequence of phyletic dwarfism. Int J Primatol 1:95-98

Lindburg D (1971) The rhesus monkey in northern India: an ecological and behavioral study. In: Rosenblum L (ed) Primate behavior. Academic Press, New York, pp 2-106

Maestripieri D (1994) Social structure, infant handling, and mothering styles in group-living Old World monkeys. Int $\mathbf{J}$ Primatol 15:531-553

Maruhashi T (1982) An ecological study of troop fissions of Japanese monkeys (Macaca fuscata yakui) on Yakushima Island, Japan. Primates 23:317-337

McKenna J (1979) The evolution of allomothering behavior among colobine monkeys: Function and opportunism in evolution. Am Anthropol 81:818-840

Melnick D, Pearl M (1987) Cercopithecines in multimale groups: genetic diversity and population structure. In: Smuts B, Cheney D, Seyfarth R, Wrangham R, Struhsaker T (eds), Primate societies. University of Chicago Press, Chicago, pp 121-134

Menard N, Vallet D (1993) Population dynamics of Macaca sylvanus in Algeria: an 8-year study. Am J Primatol 30:101-118

Mitchell C (1990) The ecological basis for female social dominance: a behavioral study of the squirrel monkey (Saimiri sciureus) in the wild. PhD thesis, Princeton University

Mitchell C, Boinski S, Schaik C van (1991) Competitive regimes and female bonding in two species of squirrel monkeys (Saimiri oerstedi and S. sciureus). Behav Ecol Sociobiol 28:55-60

Mumme RL (1992) Do helpers increase reproductive success? Behav Ecol Sociobiol 31:319-328

Napier P (1981) Catalogue of the primates in the British Museum (Natural History) and elsewhere in the British Isles, part 2: Family Cercopithecidae, subfamily Cercopithecinae. British Museum (Natural History), London

Nicolson N (1982) Weaning and the development of independence in olive baboons. $\mathrm{PhD}$ thesis, Harvard University

Nicholson N (1987) Infants, mothers, and other females. In: Smuts B, Cheney D, Seyfarth R, Wrangham R, Struhsaker T (eds) Primate societies. University of Chicago Press, Chicago, pp $330-342$

Nishida T (1983) Alloparental behavior in wild chimpanzees of the Mahale Mountains, Tanzania. Folia Primatol 41:1-33

Nishida T, Takasaki H, Takahata Y (1990) Demography and reproductive profiles. In: Nishida $\mathrm{T}$ (ed), The chimpanzees of the Mahale Mountains. University of Tokyo Press, Tokyo, pp 6397

Oates J (1977) The social life of a black-and-white colobus monkey, Colobus guereza. Z Tierpsychol 45:1-60 
Oates J, Davies AG, Delson E (1994) The diversity of living colobines. In: Davies AG, Oates J (eds) Colobine monkeys: their ecology, behaviour and evolution. Cambridge University Press, Cambridge, pp 45-73

Packer C, Lewis S, Pusey A (1992) A comparative analysis of nonoffspring nursing. Anim Behav 43:265-281

Paul A, Kuester J, Arnemann J (1996) The sociobiology of maleinfant interactions in Barbary macaques, Macaca sylvanus. Anim Behav 51:155-170

Pereira M (1993) Seasonal adjustment of growth rate and adult body weight in ring-tailed lemurs. In: Kappeler P, Ganzhorn J (eds) Lemur social systems and their ecological basis. Plenum, New York, pp 205-222

Pereira M (1995) Development and social dominance among group-living primates. Am J Primatol 35:143-175

Pereira M, Klepper A, Simons E (1987) Tactics of care for young infants by forest-living ruffed lemurs (Varecia variegata variegata): ground nests, parking and biparental guarding. Am J Primatol 13:129-144

Perry S (1995) Social relationships in wild white-faced capuchin monkeys, Cebus capucinus. PhD thesis, University of Michigan

Phillips-Conroy J, Jolly C (1981) Sexual dimorphism in two subspecies of Ethiopian baboons (Papio hamadryas) and their hybrids. Am J Phys Anthropol 56:115-129

Pook A (1984) The evolutionary role of socio-ecological factors in the development of parental care in the New World family Callitrichidae. In: Taub D (ed) Primate paternalism. Van Nostrand Reinhold, New York, pp 336-345

Powell R, Fried J (1992) Helping by juvenile pine voles (Microtus pinetorum), growth and survival of younger siblings, and the evolution of pine vole sociality. Behav Ecol 3:325-333

Purvis A (1995) A composite estimate of primate phylogeny. Philos Trans Soc Lond 348:405-421

Purvis A, Rambaut A (1994) Comparative analysis by independent contrasts (CAIC), version 2. Oxford University, Oxford

Purvis A, Rambaut A (1995) Comparative analysis by independent contrasts (CAIC): an Apple Macintosh application for analysing comparative data. Cabios 11:247-251

Riedman M (1982) The evolution of alloparental care and adoption in mammals and birds. Q Rev Biol 57:405-435

Robinson J, Janson C (1987) Capuchins, squirrel monkeys, and atelines: socioecological convergence with Old World primates. In: Smuts B, Cheney D, Seyfarth R, Wrangham R, Struhsaker $\mathrm{T}$ (eds) Primate societies. University of Chicago Press, Chicago, pp 69-82

Rodman P (1984) Foraging and social systems of orangutans and chimpanzees. In: Rodman P, Cant J (eds) Adaptations for foraging in nonhuman primates. Columbia University Press, New York, pp 134-160

Ross C (1989) Life-history strategies of primates. PhD thesis, University of London

Ross C (1991) Life history patterns of New World monkeys. Int J Primatol 12:481-502

Ross C, MacLarnon A (1995) Ecological and social correlates of maternal expenditure on infant growth in haplorhine primates. In: Pryce C, Martin R, Skuse D (eds) Motherhood in human and nonhuman primates. Karger, Basel, pp 37-46

Rudran R (1973) The reproductive cycles of two subspecies of purple-faced langurs (Presbytis senex) with relation to environmental factors. Folia Primatol 19:41-60

Sarich V, Cronin J (1976) Molecular systematics of the primates. In: Goodman M, Tashian R (eds) Molecular anthropology. Plenum, New York, pp 141-170

Savage A (1990) The reproductive biology of the cotton-top tamarin (Saguinus oedipus oedipus) in Columbia. PhD thesis, University of Wisconsin

Savage A, Giraldo L, Soto L, Snowdon C (1996) Demography, group composition, and dispersal in wild cotton-top tamarin (Saguinus oedipus) groups. Am J Primatol 37:85-100

Schaik C van (1989) The ecology of social relationships amongst female primates. In: Standen V, Foley R (eds) Comparative socioecology. Blackwell, Oxford, pp 195-218
Schultz A (1941) The relative size of the cranial capacity in primates. Am J Phys Anthropol 28:273-287

Sigg H, Stolba A, Abegglen J, Dasser V (1982) Life history of hamadryas baboons: physical development, infant mortality, reproductive parameters and family relationships. Primates $23: 473-487$

Silk J (1980) Kidnapping and female competition among captive bonnet macaques. Primates 21:100-110

Small M (1990) Alloparental behavior in barbary macaques, Macaca sylvanus. Anim Behav 39:297-306

Smuts B, Nicolson N (1989) Reproduction in wild female olive baboons. Am J Primatol 19:229-246

Soini P (1982) Ecology and population dynamics of the pygmy marmoset, Cebuella pygmaea. Folia Primatol 39:1-21

Soini P (1987) Sociosexual behavior of a free-ranging Cebuella pygmaea (Callitrichidae, Platyrrhini) troop during postpartum estrus of its reproductive female. Am J Primatol 13:223-230

Solomon N (1991) Current indirect fitness benefits associated with philopatry in juvenile prairie voles. Behav Ecol Sociobiol 29:277-282

Stanford C (1992) Costs and benefits of allomothering in wild capped langurs (Presbytis pileata). Behav Ecol Sociobiol 30:2934

Stanford C, Wallis J, Matama H, Goodall J (1994) Patterns of predation by chimpanzees on red colobus monkeys in Gombe National Park, 1982-1991. Am J Phys Anthropol 94:213-228

Struhsaker T, Leland L (1987) Colobines: infanticide by adult males. In: Smuts B, Cheney D, Seyfarth R, Wrangham R, Struhsaker T (eds), Primate societies. University of Chicago Press, Chicago, pp 83-97

Takahata Y, Ihobe H, Idani G (in press) Comparing copulations of chimpanzees and bonobos: do females exhibit proceptivity or receptivity? In: McGrew W, Marchant, L, Nishida T (eds) Great ape societies. Cambridge University Press, Cambridge

Tardif S (1994) Relative energetic cost of infant care in smallbodied neotropical primates and its relation to infant-care patterns. Am J Primatol 34:133-143

Turner T, Anapol F, Jolly CJ (1994) Body weights of adult vervet monkeys (Cercopithecus aethiops) at four sites in Kenya. Folia Primatol 63:177-179

Uehara S, Nishida T (1987) Body weights of wild chimpanzees (Pan troglodytes) of the Mahale Mountains National Park, Tanzania. Am J Phys Anthropol 72:315-321

Vogel C (1984) Patterns of infant-transfer within two troops of common langurs (Presbytis entellus) near Jodhpur. Testing hypotheses concerning the benefits and risks. In: Roonwal M, Mohnot S, Rathore N (eds) Current primate researches. University of Jodhpur, Jodhpur, pp 361-379

Wahome J, Rowell T, Tsingalia H (1993) The natural history of de Brazza's monkey in Kenya. Int J Primatol 14:445-466

Watts D (1991) Mountain gorilla reproduction and sexual behavior. Am J Primatol 24:211-225

Watts D (1994) Agonistic relationships between female mountain gorillas (Gorilla gorilla beringei). Behav Ecol Sociobiol 34:347358

Whitten P (1984) Female reproductive strategies among vervet monkeys. PhD thesis, Harvard University

Williams L, Gibson S, McDaniel M, Bazzel J, Barnes S, Abee C (1994) Allomaternal interactions in the Bolivian squirrel monkey (Saimiri boliviensis boliviensis). Am J Primatol 34:145156

Wright P (1984) Biparental care in Aotus trivirgatus and Callicebus moloch. In: Small M (ed) Female primates. Alan Liss, New York, pp 59-75

Wright P (1990) Patterns of paternal care in primates. Int J Primatol 11:89-102

Zucker E, Kaplan J (1981) Allomaternal behavior in a group of free-ranging patas monkeys. Am J Primatol 1:57-64

Communicated by P.M. Kappeler 